\title{
REVIEW
}

Open Access

\section{A meta-analysis of the efficacy and safety of adjuvant sorafenib for hepatocellular carcinoma after resection}

\author{
Shenglan Huang ${ }^{1}$, Dan $\mathrm{Li}^{1}$, LingLing Zhuang ${ }^{2}$, Liying Sun ${ }^{1}$ and Jianbing $\mathrm{Wu}^{{ }^{*}}$
}

\begin{abstract}
Background: Sorafenib was reported as a useful adjuvant treatment in patients with hepatocellular carcinoma who underwent surgical resection. However, its therapeutic value remains controversial. This meta-analysis examined the available data regarding the efficacy and safety of sorafenib in patients with hepatocellular carcinoma after radical surgery.

Methods: The meta-analysis was conducted according to the Preferred Reporting Items for Systematic Reviews and Meta-Analyses guidelines. The protocol was registered in advance with PROSPERO (CRD42021233868). We searched PubMed, Embase, Cochrane Library, and Web of Science to identify eligible studies. Overall survival, recurrence-free survival, and recurrence rates were analyzed, and adverse events were reviewed. Hazard ratios or pooled risk ratios with $95 \% \mathrm{Cls}$ were collected and analyzed using STATA version 12.0 in a fixed-effects or random-effects meta-analysis model.
\end{abstract}

Results: In total, 2655 patients from 13 studies were ultimately included in this meta-analysis. The combined results illustrated that sorafenib was associated with better overall survival than the control (hazard ratio $=$ $0.71,95 \% \mathrm{Cl}=0.59-0.86 ; P<0.001$ ). Similarly, the drug also improved recurrence-free survival (hazard ratio $=$ $0.68,95 \% \mathrm{Cl}=0.54-0.86, P=0.001)$. Combined data revealed that patients treated with sorafenib after resection had a lower recurrence rate (pooled risk ratio $=0.78,95 \% \mathrm{Cl}=0.68-0.90, P<0.001$ ). The primary adverse events were hand-foot skin reaction, fatigue, and diarrhea of mild-to-moderate severity, whereas grade 4 adverse events were rare $(<1 \%)$.

Conclusions: This meta-analysis demonstrated that adjuvant sorafenib therapy after resection in patients with hepatocellular carcinoma could prolong overall survival and recurrence-free survival and reduce recurrence rates without intolerable side effects. However, more evidence is needed before reaching a definitive conclusion.

Keywords: Hepatocellular carcinoma, HCC, Sorafenib, Resection, Meta-analysis

\footnotetext{
* Correspondence: hhgwjb@163.com

'Department of Oncology, The Second Affiliated Hospital of Nanchang

University, No. 1, Minde Road, Nanchang 330006, Jiangxi Province, People's

Republic of China

Full list of author information is available at the end of the article
}

(c) The Author(s). 2021 Open Access This article is licensed under a Creative Commons Attribution 4.0 International License, which permits use, sharing, adaptation, distribution and reproduction in any medium or format, as long as you give appropriate credit to the original author(s) and the source, provide a link to the Creative Commons licence, and indicate if changes were made. The images or other third party material in this article are included in the article's Creative Commons licence, unless indicated otherwise in a credit line to the material. If material is not included in the article's Creative Commons licence and your intended use is not permitted by statutory regulation or exceeds the permitted use, you will need to obtain permission directly from the copyright holder. To view a copy of this licence, visit http://creativecommons.org/licenses/by/4.0/ The Creative Commons Public Domain Dedication waiver (http://creativecommons.org/publicdomain/zero/1.0/) applies to the data made available in this article, unless otherwise stated in a credit line to the data. 


\section{Background}

Liver cancer is currently the fourth common cause of cancer-related mortality and the sixth most common cause of cancer, and the World Health Organization predicts that more than one million patients will die from liver cancer in $2030[1,2]$. The prevalence of hepatocellular carcinoma (HCC), which accounts for 75-80\% of liver cancers, has increased in recent years [3]. Approximately 700,000 new cases of HCC are detected annually, with more than half occurring in developing countries. In addition, 75\% of HCC-related deaths occur in Asian countries [4].

At an early stage of $\mathrm{HCC}$ (single nodule $\leq 5 \mathrm{~cm}$ in diameter or $2-3$ nodules $\leq 3 \mathrm{~cm}$ in diameter), potentially curative treatments, including surgical resection, radiofrequency ablation (RFA), and liver transplantation, can be applied [5]. In theory, the best treatment option is liver transplantation, but the scarcity of liver donors limits its applicability; hence, most patients undergo resection or RFA as the first-line treatment. Prior research found that 5-year overall survival (OS) rates for the RFA and resection groups were $54.78 \%$ and $75.65 \%$, respectively. Regarding solitary huge HCC, a previous study demonstrated that portal vein ligation combined with staged hepatectomy provided superior outcomes to transarterial chemoembolization (TACE) [6]. Even very elderly HCC patients (aged 80 years or older) could potentially benefit from hepatectomy if patients have a good general status, and the prognoses of very elderly patients were similar to nonelderly individuals [7]. Although resection may provide better survival and lower recurrence rates for patients with HCC [8], the recurrence rate after surgical resection remains as high as $50 \%$ after 3 years and $70 \%$ at 5 years [9]. Factors related to the postoperative recurrence of $\mathrm{HCC}$ include the histological tumor grade, presence of vascular invasion, presence of microsatellite nodules, tumor size, and resection margin [10]. Thus, the long-term prognosis after surgery remains unsatisfactory, and systemic adjuvant therapy plays an important role in the treatment of $\mathrm{HCC}$ after resection.

Currently, there is no standard adjuvant therapy for HCC after resection. On the basis of its mechanism of inhibiting tumor cell proliferation and angiogenesis, sorafenib has been widely used after gaining approval from the US Food and Drug Administration for the treatment of HCC. Moreover, it is the only approved treatment recommended by the American Association for the Study of Liver Diseases for patients with advanced and unresectable HCC. However, whether sorafenib can suppress postoperative recurrence and consequently prolong survival remains controversial. At present, several retrospective studies have found that sorafenib can reduce the postoperative recurrence rate and improve long-term survival rates in patients with HCC [11-14]. A case-control study revealed that adjuvant sorafenib could prolong disease-free survival and OS in patients with $\mathrm{HCC}$ beyond the Milan criteria after orthotopic liver transplantation [15]. Conversely, the STORM trial indicated that sorafenib is not an effective intervention in the adjuvant setting for $\mathrm{HCC}$ following resection or RFA [16]. To resolve this controversy, we undertook this meta-analysis to investigate whether adjuvant sorafenib is useful in patients with HCC after resection.

\section{Methods \\ Literature search}

This meta-analysis was conducted in accordance with the Preferred Reporting Items for Systematic Reviews and Meta-Analyses guidelines. We comprehensively searched PubMed, Embase, Cochrane Library, and Web of Science using $\mathrm{MeSH}$ terms and keywords (liver neoplasm, hepatectomy, sorafenib) to identify relevant clinical trials performed before January 2021. The publication language was limited to English. First, the title and abstract were filtered, and then the reference lists of the retrieved articles were analyzed. The protocol was registered with PROSPERO in advance (CRD42021233868).

\section{Inclusion and exclusion criteria}

Studies eligible for inclusion in this meta-analysis had to meet all of the following criteria: (1) patients with resectable HCC who only underwent surgical resection; (2) the intervention was sorafenib therapy after resection versus observation or placebo before tumor progression or recurrence; (3) the study design was limited to randomized control trials (RCTs), retrospective or prospective cohort studies, and case-control studies; and (4) outcome measures, including OS, recurrence-free survival (RFS), and/or the recurrence rate, were available or could be calculated.

The exclusion criteria were as follows: (1) reviews, abstract, case reports, and letters; (2) the absence of sufficient data to estimate hazard ratios (HRs) and 95\% CIs; (3) publication in languages other than English; and (4) the inclusion of duplicate data or repeat analyses.

\section{Data extraction and quality assessment}

After preliminarily evaluating the relevant articles retrieved from the databases mentioned above, two reviewers (Shenglan Huang and Dan Li) screened and extracted relevant articles independently by reading the titles and abstracts. The number of studies in each screening procedure and the reasons for exclusion were recorded. The reviewers then carefully read the full texts of the included studies and extracted useful information. The following information was collected: first author, publication year, country or region, study design, sample 
size, patient demographics, tumor characteristics, followup duration, treatment duration, outcome measures (OS, RFS, recurrence rate) with HRs/risk ratios (RRs) and 95\% CIs, adverse events, and type of survival analysis (univariate or multivariate). If both univariate and multivariate analyses were performed in the study, the HRs of multivariate analysis were preferred. Two independent authors (Shenglan Huang and Dan Li) used the Newcastle-Ottawa Scale (NOS) to evaluate the quality of case-control or cohort studies. The Jadad scoring system was applied for RCTs. Jianbing Wu resolved any lack of clarity or disagreement.

\section{Statistical analysis}

HRs and 95\% CIs were obtained directly from the articles or calculated from the Kaplan-Meier curves using Engauge Digitizer version 4.1 (http://digitizer. sourceforge. net/). Pooled HRs and their 95\% CIs were estimated for OS and RFS. HR $<1$ indicated that sorafenib was associated with a better prognosis in patients with HCC after resection. Pooled RRs with 95\% CIs were estimated for recurrence rates, and $R R<1$ indicated favorable outcomes in the sorafenib group. Cochran's $Q$ test and Higgins $I^{2}$ statistic were applied to assess the heterogeneity of the included studies. Significant heterogeneity among the studies was indicated by $P<0.05$ or $I^{2}>50 \%$, and the random-effects model was adopted to calculate the pooled HRs. Otherwise, the fixed-effects model was used. Subgroup and sensitivity analyses were performed to explore the heterogeneity among the results of different studies. Begg's test and Egger's linear regression analysis were conducted to evaluate publication bias. For all outcomes, $P<0.05$ denoted statistical significance. All statistical analyses were conducted using STATA version 12.0 (STATA Corporation, College Station, TX, USA).

\section{Results}

\section{Study selection and quality assessment}

In total, 956 records were retrieved through the preliminary search strategies, including 582 records from PubMed, 147 from Embase, 140 from Cochrane Library, 83 from Web of Science, and 4 from other databases. After removing the duplicates, 712 articles were further screened. By reading the titles and abstracts, 679 irrelevant studies were excluded, and the remaining 23 articles were carefully checked according to the inclusion and exclusion criteria. Ten articles that did not meet the inclusion criteria were excluded. Finally, 13 comparative studies involving 2655 patients were included in the meta-analysis [11-14, 16-24]. The screening process of the study is presented in Fig. 1.

Among the 13 studies included in the final analysis, 11 studies were conducted in China; one study was undertaken across 202 sites (hospitals and research centers) in 28 countries throughout the Americas, the Asia-Pacific region, and Europe; and one study included Caucasians. The 13 studies included 10 retrospective studies and 3 prospective studies. A total of 1039 patients in the studies received sorafenib. The eligible studies were all published from 2014 to 2020. The characteristics of each study are listed in Table 1.

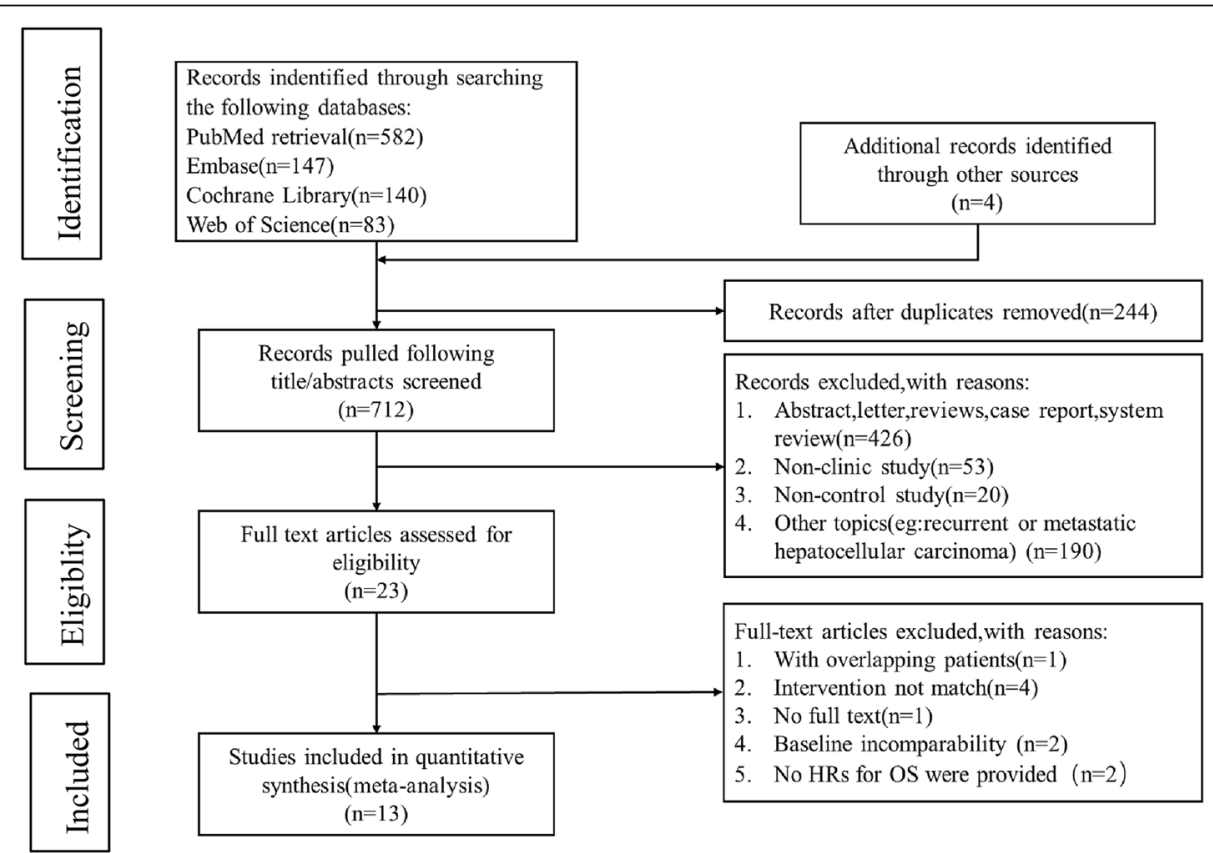

Fig. 1 Flow chart of the study selection 


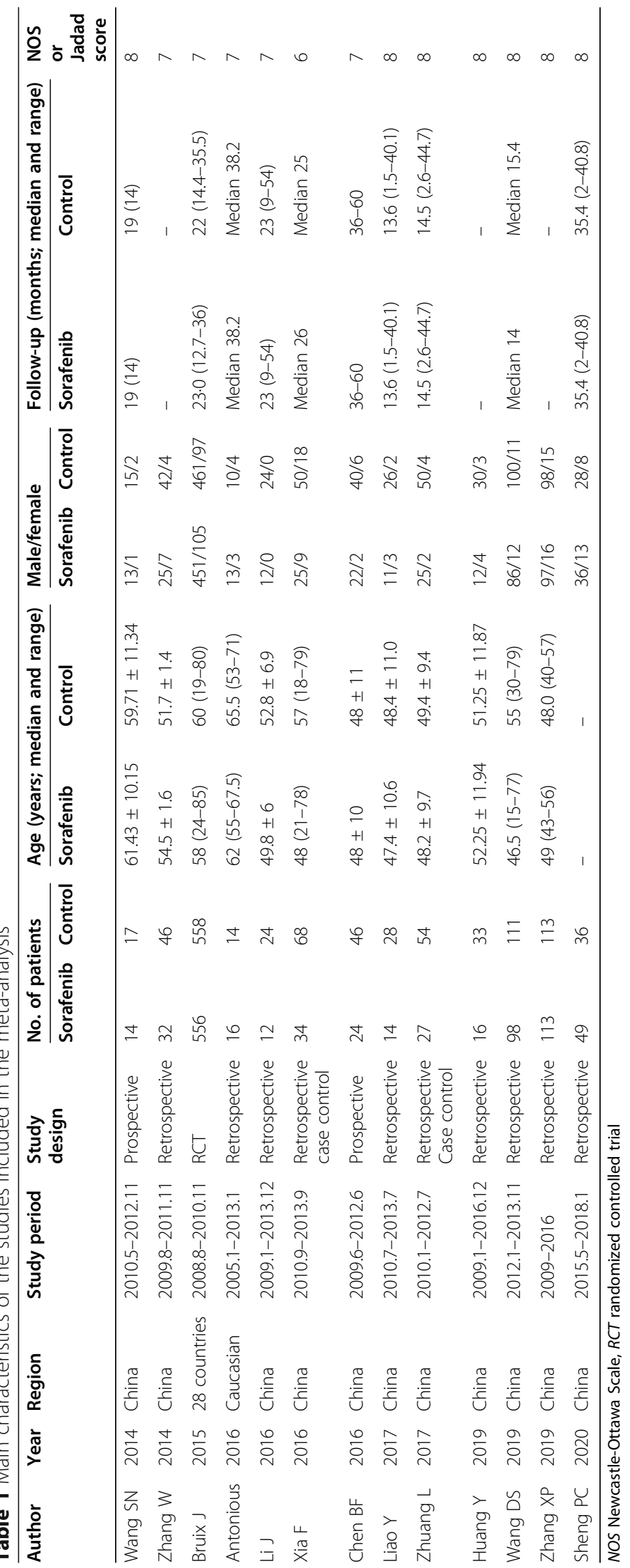


Regarding sorafenib treatment, 12 of the included studies used an initial dose of $400 \mathrm{mg}$ twice daily, and doses were adjusted according to the safety findings and patient tolerability [11-14, 16-24]. Tumor size, which differed among the studies, was recorded in all included studies. Treatment duration was described in seven studies, ranging from 4 to 70.97 months $[12-14,16,19,20$, 23]. The characteristics of the sorafenib treatment group are listed in Table 2.

The NOS was applied in 12 studies. The NOS was $\geq 6$ in all studies, indicating that the included studies had mild-to-moderate risks of bias. The Jadad score was applied in the remaining one RCT, and the score was 7 . The results of the quality assessment in the included studies are presented in Table 1.

\section{Treatment outcomes}

\section{Overall survival}

Ten studies involving 1995 patients presented data for OS. Among them, four studies provided multivariateadjusted HRs (Table 2). The pooled results revealed that sorafenib treatment led to better OS than the control after resection $(\mathrm{HR}=0.71,95 \% \mathrm{CI}=0.59-0.86, P<$ 0.001 ), and no significant heterogeneity was observed among the studies $\left(I^{2}=47.7 \%, P=0.046\right)$, as presented in Fig. 2.

Begg's funnel plot and Egger's test were used to evaluate publication bias. Publication bias for OS was detected ( $\mathrm{Pr}$ $>|z|=0.283$ for Begg's test and $P>|t|=0.003$ for Egger's test). The corrected pooled HR for OS was not changed after using the "trim and fill" method to adjust for publication bias $(\mathrm{HR}=0.71,95 \% \mathrm{CI}=0.59-0.86, P<0.001)$.

\section{Recurrence-free survival}

Ten trials reported a correlation between sorafenib treatment and RFS. The forest plot indicated that the HR for RFS was 0.68 (95\% CI $=0.54-0.86, P=0.001$, Fig. 3 ). The pooled results revealed dramatically higher RFS in patients who received sorafenib. The data were analyzed using a random-effects model, and $I^{2}$ for heterogeneity was $55 \%$. Subgroup analysis was then conducted according to region, study design, analysis type (univariate or multivariate), and the presence of vascular invasion. As presented in Table 3, RFS was higher in Chinese patients in the fixed-effects model (pooled $\mathrm{HR}=0.68,95 \% \mathrm{CI}=$ $0.57-0.81, P=0.001$ ). Patients with vascular invasion obtained a greater RFS benefit from sorafenib therapy according to the random-effects model, and $I^{2}$ for heterogeneity was $52.5 \%$ (pooled $\mathrm{HR}=0.51,95 \% \mathrm{CI}=$ $0.35-0.74, P<0.001)$. Meanwhile, the pooled HRs were $0.53(95 \% \mathrm{CI}=0.14-1.99, P=0.35)$ for prospective studies and 0.7 (95\% CI $=0.58-0.83, P<0.001)$ for retrospective studies, and those for univariate and multivariate analyses were $0.91(95 \% \mathrm{CI}=0.78-1.07, P=0.274)$ and $0.51(95 \% \mathrm{CI}=0.35-0.74, P<0.001)$, respectively.

Sensitivity analysis was performed using a "one-study removed" model. The results illustrated that the observed pooled HR for RFS was not significantly affected

Table 2 Main characteristics of patients treated with sorafenib in the included studies

\begin{tabular}{|c|c|c|c|c|c|c|c|c|c|}
\hline Author & Year & $\begin{array}{l}\text { Sample size } \\
\text { (sorafenib) }\end{array}$ & Media age & Male (\%) & Tumor size $(\mathrm{cm})$ & HRs & $\begin{array}{l}\text { Initial dose } \\
\text { (sorafenib) }\end{array}$ & $\begin{array}{l}\text { Duration (months; } \\
\text { median and range) }\end{array}$ & Risk factors \\
\hline Wang SN & 2014 & 14 & 61.43 & 92.9 & Median $6.26 \pm 2.12$ & UV/MV & $400 \mathrm{mg}$ & 4 & MVI (78.16\%) \\
\hline Zhang W & 2014 & 32 & 51.7 & 78.1 & Median $5.7 \pm 0.6$ & UV/MV & $400 \mathrm{mg}$ & - & $\begin{array}{l}\text { Multiple tumors } \\
(53.1 \%) \\
\text { Portal vein } \\
\text { thrombosis (25\%) } \\
\text { TNM stage III } \\
(31.2 \%)\end{array}$ \\
\hline Bruix J & 2015 & 556 & 58 & 81 & Median 3.5 (1.0-20) & UV & $400 \mathrm{mg}$ & $12.5(2.6-35.8)$ & MVI (68\%) \\
\hline Antonious & 2016 & 16 & 65.5 & 81.3 & Median 7.8 (6.0-9.8) & UV & $200-400 \mathrm{mg}$ & - & MVI (61.5\%) \\
\hline Li J & 2016 & 12 & 49.8 & 100 & Largest $9.8 \pm 2.1$ & UV & $400 \mathrm{mg}$ & - & $\begin{array}{l}\text { BCLC C (100\%) } \\
\text { portal vein } \\
\text { Thrombus (100\%) }\end{array}$ \\
\hline Xia F & 2016 & 34 & 48 & 73.5 & Media $6.4(2.8-20.2)$ & MV & $400 \mathrm{mg}$ & 22.9 & BCLC C (100\%) \\
\hline Chen BF & 2016 & 24 & 48 & 91.67 & Media $4.4(0.8-10.5)$ & UV & $400 \mathrm{mg}$ & 6 & - \\
\hline Liao Y & 2017 & 14 & 47.4 & 78.6 & $<10(71.4 \%) \geq 10(28.6 \%)$ & UV/MV & $400 \mathrm{mg}$ & $14.3(2.6-24.2)$ & Tumor size \\
\hline Zhuang L & 2017 & 27 & 48.2 & $92.6 \%$ & Media $7.8 \pm 3.9$ & UV/MV & $400 \mathrm{mg}$ & $7.3(5.8-8.9)$ & $\mathrm{BCLC} B / \mathrm{C}$ \\
\hline Huang Y & 2019 & 16 & 52.25 & $75 \%$ & $\leq 5(37.5 \%)>5(62.5 \%)$ & UV/MV & $400 \mathrm{mg}$ & $45.52(1.10-70.97)$ & MVI \\
\hline Wang DS & 2019 & 98 & 46.5 & 87.76 & Largest $7.91 \pm 3.42$ & UV & $400 \mathrm{mg}$ & - & $B C L C B / C$ \\
\hline Zhang XP & 2019 & 147 & 47 & 87.8 & Media 6.0 (4.0-9.6) & UV & $400 \mathrm{mg}$ & - & MVI \\
\hline Sheng PC & 2020 & 49 & - & 73.4 & $\leq 5(58.3 \%)>5(41.7 \%)$ & UV/MV & $400 \mathrm{mg}$ & - & MVI \\
\hline
\end{tabular}




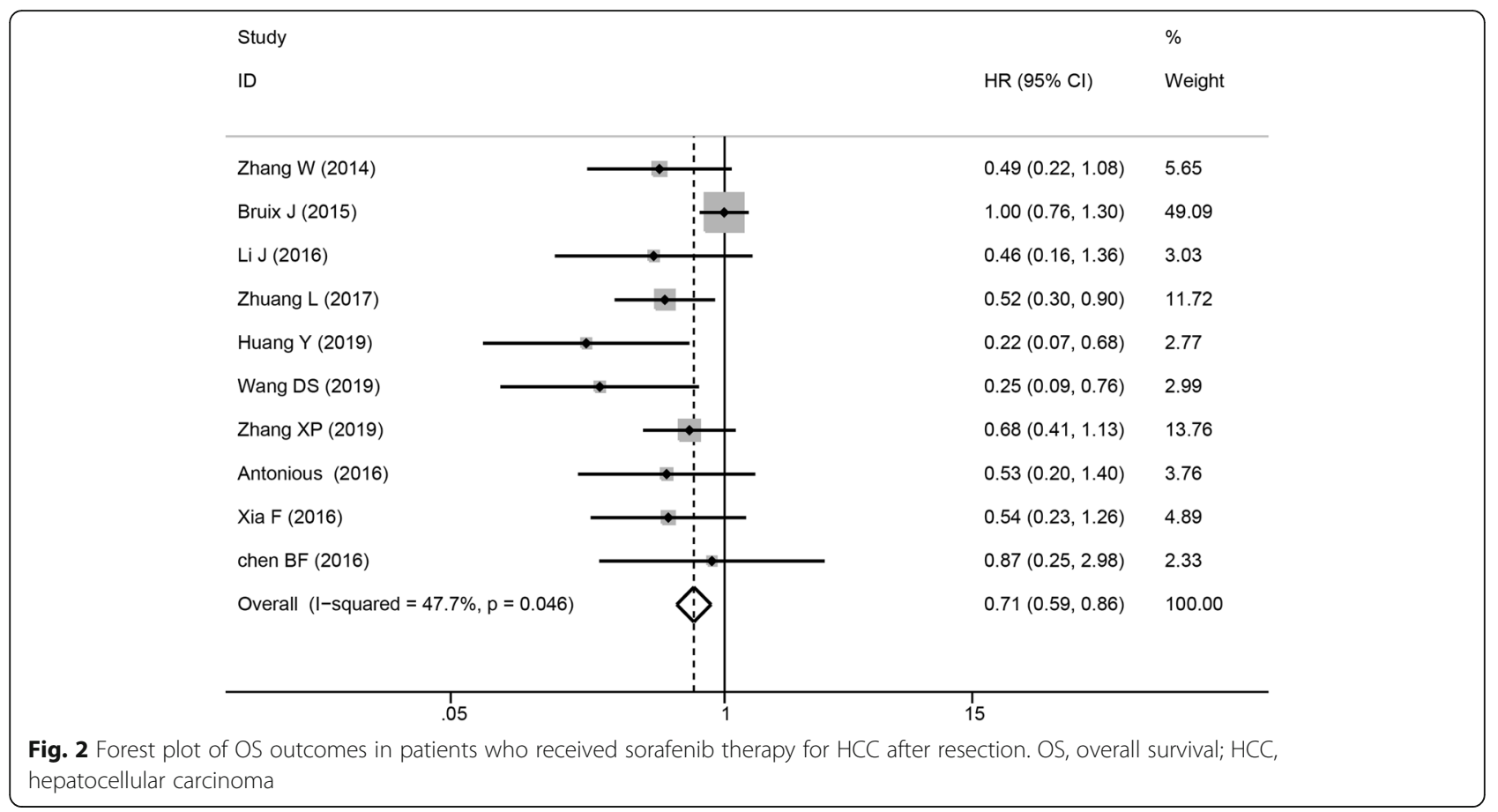

by removing any single study (Fig. 4). Publication bias for RFS was detected $(\operatorname{Pr}>|z|=0.074$ for Begg's test and P > $|t|=0.005$ for Egger's test). The corrected pooled HR for RFS was not changed after using the trim and fill method to adjust for publication bias in the random-effects model $(\mathrm{HR}=0.68,95 \% \mathrm{CI}=0.54-0.86, P=0.001)$.

\section{Recurrence rate}

Eight studies involving 1482 patients reported recurrence rates for sorafenib as adjuvant therapy in patients with resectable $\mathrm{HCC}$. The combined data revealed that sorafenib treatment after resection was associated with a lower recurrence rate (pooled $\mathrm{RR}=0.78,95 \% \mathrm{CI}=$

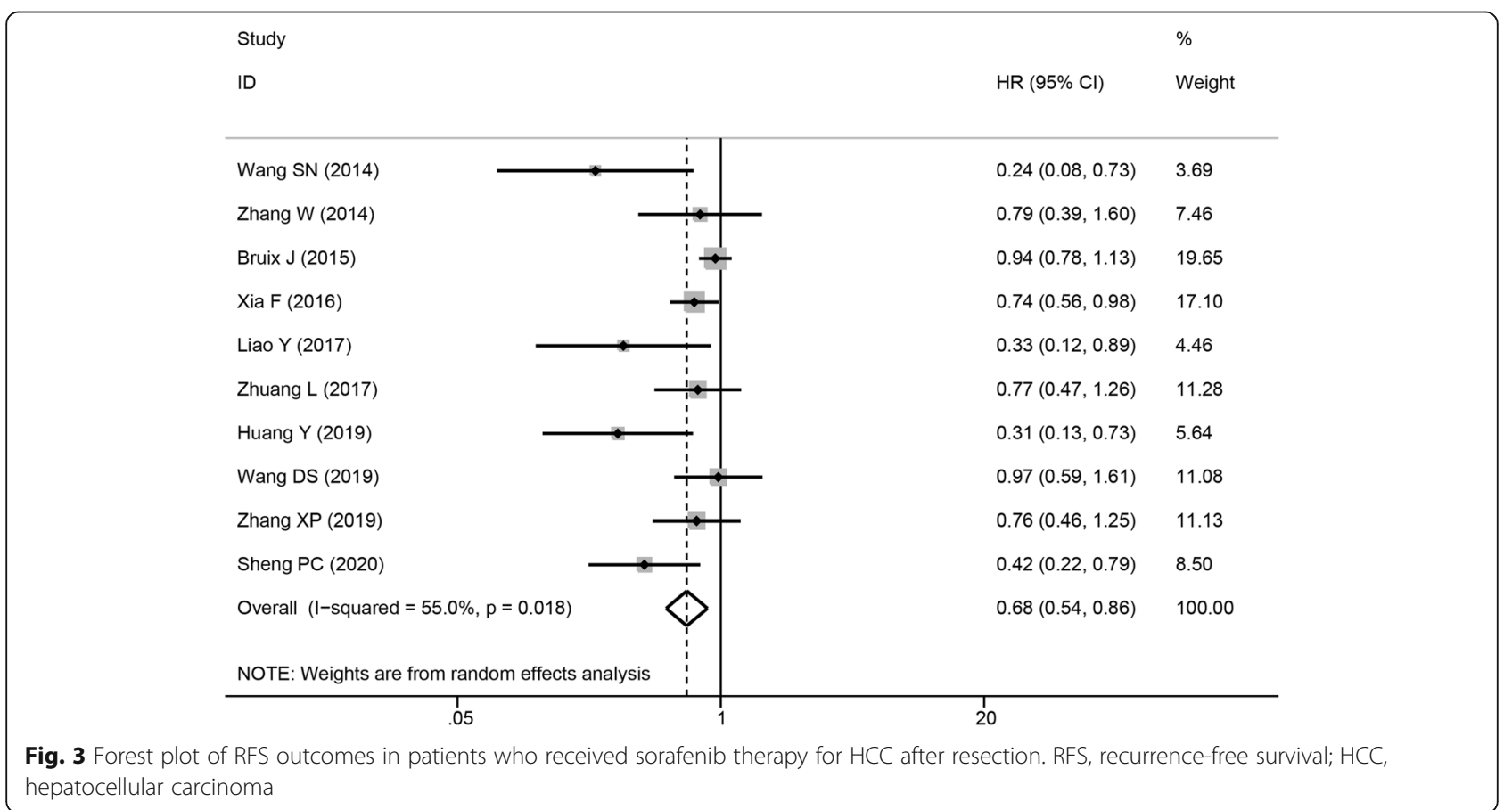


Table 3 HRs for RFS by subgroup

\begin{tabular}{|c|c|c|c|c|c|c|c|c|}
\hline \multirow[t]{2}{*}{ Subgroups } & \multirow{2}{*}{$\begin{array}{l}\text { No. of } \\
\text { studies }\end{array}$} & \multirow{2}{*}{$\begin{array}{l}\text { No. of } \\
\text { patients }\end{array}$} & \multicolumn{2}{|c|}{ Random-effects model } & \multicolumn{2}{|c|}{ Fixed-effects model } & \multicolumn{2}{|c|}{ Heterogeneity } \\
\hline & & & $\mathrm{HR}(95 \% \mathrm{Cl})$ & $P$ & HR $(95 \% \mathrm{Cl})$ & $P$ & $I^{2}$ & $P h$ \\
\hline \multicolumn{9}{|l|}{ Regions } \\
\hline China & 9 & 397 & $0.63(0.49-0.81)$ & 0.000 & $0.68(0.57-0.81)$ & 0.000 & $41.8 \%$ & 0.089 \\
\hline Other countries & 1 & 556 & $0.94(0.78-1.13)$ & 0.513 & $0.94(0.78-1.13)$ & 0.513 & $0 \%$ & 0 \\
\hline \multicolumn{9}{|l|}{ Study design } \\
\hline Prospective & 2 & 570 & $0.53(0.14-1.99)$ & 0.350 & $0.91(0.75-1.09)$ & 0.292 & $82 \%$ & 0.018 \\
\hline Retrospective & 8 & 383 & $0.67(0.53-0.85)$ & 0.001 & $0.7(0.58-0.83)$ & 0.000 & $32.3 \%$ & 0.170 \\
\hline \multicolumn{9}{|l|}{ Root of HRs } \\
\hline Univariate & 4 & 799 & $0.91(0.78-1.07)$ & 0.274 & $0.91(0.78-1.07)$ & 0.274 & $52.8 \%$ & 0.060 \\
\hline Multivariate & 6 & 154 & $0.51(0.35-0.74)$ & 0.000 & $0.62(0.5-0.76)$ & 0.000 & $0 \%$ & 0.84 \\
\hline \multicolumn{9}{|c|}{ Risk of factor (with vascular invasion or not) } \\
\hline Yes & 6 & 240 & $0.51(0.35-0.74)$ & 0.000 & $0.62(0.5-0.76)$ & 0.000 & $52.4 \%$ & 0.062 \\
\hline No & 4 & 713 & $0.92(0.78-1.07)$ & 0.278 & $0.92(0.78-1.07)$ & 0.278 & $0 \%$ & 0.855 \\
\hline
\end{tabular}

$H R$, hazard ratio, $R F S$ recurrence-free survival

0.68-0.90, $P<0.001)$, and no significant heterogeneity was found $\left(I^{2}=2.3 \%, P=0.412\right.$, Fig. 5).

\section{Adverse events}

Seven studies provided adverse event data for adjuvant sorafenib treatment, although two studies only described the total incidence of adverse events without mentioning specific events. The most common sorafenib-related adverse reactions included hand-foot-skin reaction (HFSR), fatigue, alopecia, rash or desquamation, hypertension, anorexia, hematological events, transaminase elevation, and diarrhea (Table 4). HFSR was the most frequent event in four studies. Fatigue and diarrhea were also frequent events. According to the Common Terminology Criteria for Adverse Events, most adverse events were mild to moderate in severity, and grade 4 adverse reactions were rare $(<1 \%)$. Severe adverse events represent the major reason for sorafenib dose modification. All drug-related adverse events were resolved with treatment, and no adverse event-related deaths occurred.

\section{Discussion}

In this meta-analysis, we investigated 13 comparative studies, including $1 \mathrm{RCT}$ and 12 retrospective studies, to explore the effects of adjuvant sorafenib therapy on survival and recurrence in patients with HCC who

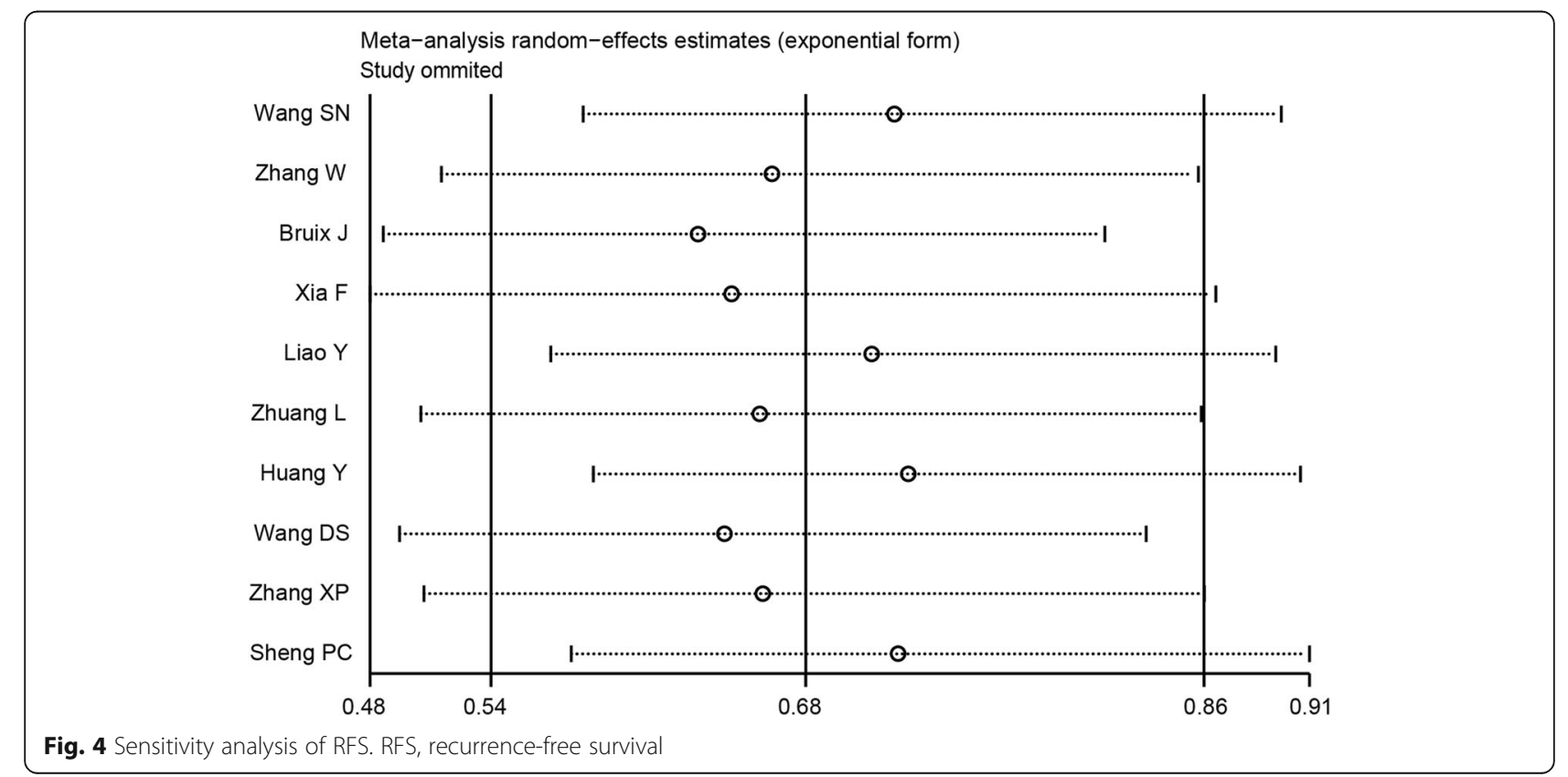




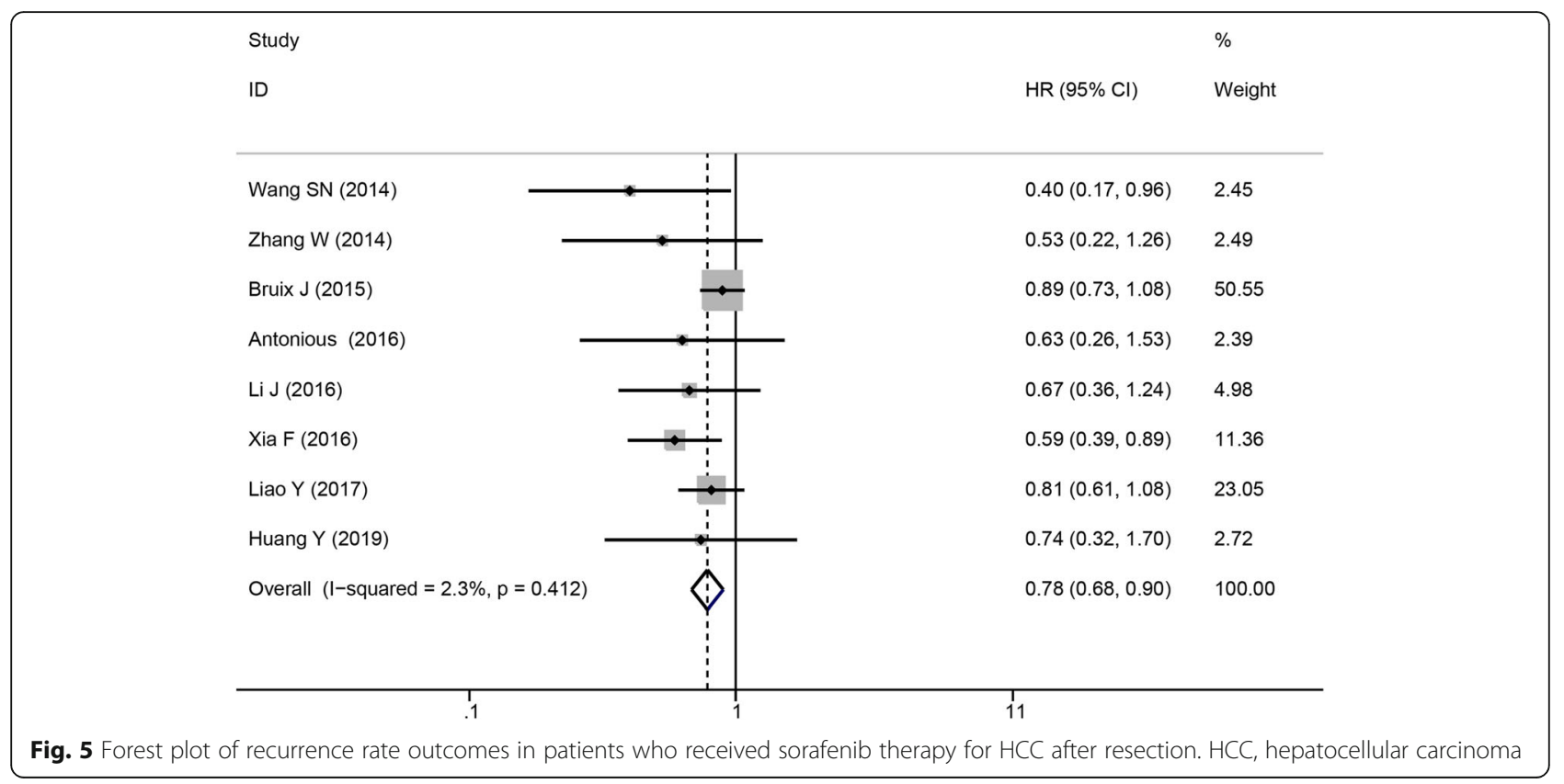

underwent radical resection. Our study found that adjuvant sorafenib can both improve RFS (HR $=0.68,95 \%$ $\mathrm{CI}=0.54-0.86, P=0.001)$, reduce recurrence rates $(\mathrm{HR}$ $=0.78,95 \% \mathrm{CI}=0.68-0.90, P<0.001)$, and prolong OS $(\mathrm{HR}=0.71,95 \% \mathrm{CI}=0.59-0.86, P<0.001)$.

The pooled outcomes of our meta-analysis illustrated that the use of sorafenib significantly prolonged OS. This result was inconsistent with that of a previous metaanalysis [25]. One of the reasons for the contradiction might be the differences in sample sizes and patient characteristics. The present study included more studies than the previous analysis, which is preferable in a metaanalysis setting. The previous meta-analysis only included six studies, and patients were divided into the control (reference) and sorafenib groups. However, each subgroup analysis included no more than four groups of data. Additionally, the former analysis did not conduct publication bias using funnel plots or Egger's test, precluding definitive conclusions. Among the four additional studies, most patients underwent liver resection for HCC with histologically confirmed microvascular invasion or moderate-toadvanced HCC, which might explain the inconsistent results. However, there was publication bias concerning OS in this study, although when the trim and fill method was used to adjust for publication bias, the corrected pooled HR for OS did not change, which might be attributable to the number of original studies. When the study by Bruix was omitted [16], the sorafenib group still had better OS (HR $=0.52,95 \% \mathrm{CI}=0.4-0.68, P<0.001)$. No heterogeneity was observed among the studies $\left(I^{2}=0 \% P\right.$ $=0.68)$, and no obvious publication bias was found $(\operatorname{Pr}>$ $|z|=0.175$ for Begg's test and $P>|t|=0.167$ for Egger's test).

Sorafenib, as a multi-target, multi-kinase inhibitor, both suppresses tumor proliferation by inhibiting serine/ threonine kinases and blocking the RAF/MEK/ERK pathway and prevents tumor angiogenesis by inhibiting vascular endothelial growth factor receptors 1-3, platelet-derived growth factor receptor $\beta$, FMS-like tyrosine kinase 3 , serine/threonine kinases (c-RAF and b-RAF), and epithelial growth factor receptor, thereby suppressing cancer growth and metastasis. Thus, the drug inhibits both tumor angiogenesis and tumor cell proliferation [12]. The availability of sorafenib for HCC treatment has been wildly acknowledged. In the phase III Sorafenib HCC Assessment Randomized Protocol (SHARP) study [2], sorafenib improved OS in patients with advanced, unresectable HCC by 3 months, and the safety and modest efficacy of sorafenib were validated in patients from the Asia-Pacific region [26]. A metaanalysis including 5125 advanced HCC patients revealed that there were significant improvements in overall survival (OS), overall response rate (ORR), and time to progression in patients who received TACE and sorafenib compared with the effects of TACE monotherapy [27]. Moreover, sorafenib can serve as a preoperative adjuvant therapy and downstage patients with large HCC, allowing further surgical resection [28]. Thus, the antiangiogenic, antiproliferative, and proapoptotic properties of sorafenib make it an ideal option after hepatectomy in theory. Animal studies revealed that sorafenib could control tumor growth and inhibit tumor recurrence after 


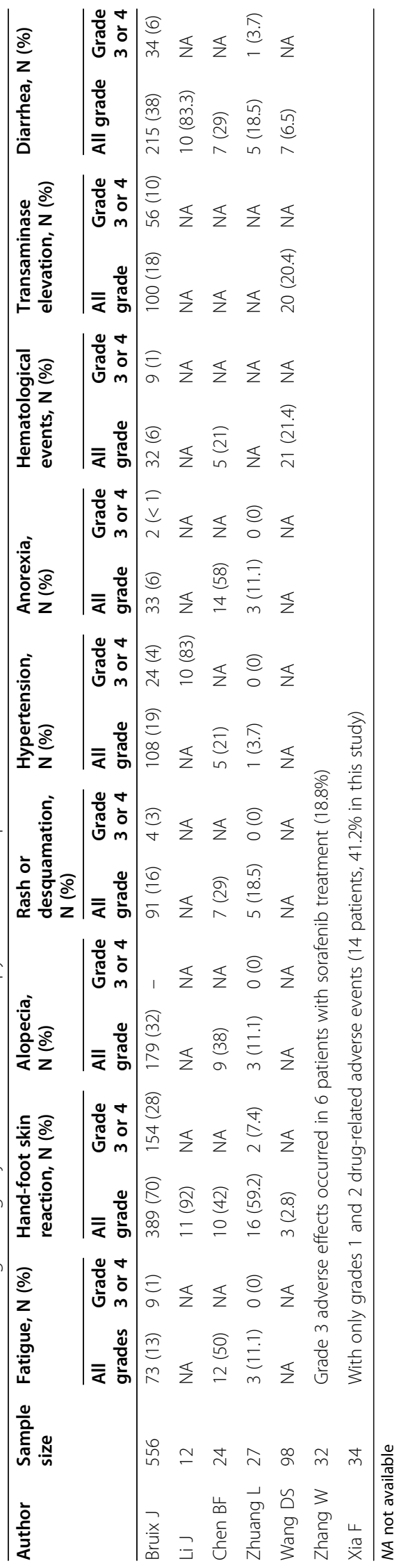


hepatectomy [29, 30]. However, clinical studies reported inconsistent results, mainly attributable to the high biological heterogeneity across HCC; thus, sorafenib might only have efficacy in certain patients or against particular activated signaling pathways. The Barcelona Clinic Liver Cancer staging and Child-Pugh cirrhosis classifications are the critical criteria for selecting patients with HCC who are suitable for sorafenib therapy [31]. In addition, an inflammatory microenvironment and circulating immune cells and cytokines play a significant role in the prognosis of HCC [32, 33]. To date, Hu et al. [32] used a systemic immune-inflammation index to forecast the prognosis of patients after curative resection. Other factors, including the viral status [34], adverse events attributable to sorafenib [35], fibroblast growth factor 3/ fibroblast growth factor 4 amplification, angiogenic factors (angiopoietin-2 and vascular endothelial growth factor-A) [36, 37], have been reported to impair the efficacy of sorafenib. Several included studies reported that treatment prior to resection, tumor size, multiple tumors, intrahepatic metastasis, and vascular invasion were risk factors associated with the efficacy of sorafenib treatment.

Several limitations of this analysis must be considered. First, the inclusion of studies with different study designs, including retrospective cohort studies, retrospective case-control studies, and an RCT, might have affected the outcome of the analysis. Hence, RCTs with larger patient populations are needed to confirm the present outcomes. Second, only a small number of studies were included (13 articles), and included studies were constrained to those published in the English language, resulting in selection biases. Moreover, publication bias was observed for OS, and high heterogeneity was observed for RFS, which might affect the interpretation of the results of this metaanalysis. Thus, definitive conclusions concerning the efficacy of sorafenib in patients with HCC after resection could not be drawn.

\section{Conclusions}

In summary, this meta-analysis demonstrated that sorafenib as an adjuvant treatment in patients who underwent resection for HCC could prolong OS, improve RFS, and reduce recurrence rates without intolerable adverse effects. Sorafenib might be an effective option for preventing HCC recurrence after resection. However, the results of this meta-analysis need to be interpreted with caution because sorafenib might only be effective in patients with certain risk factors or those with particular activated signaling pathways. In the future, more well-designed, largescale studies are needed to confirm these findings.

\section{Abbreviations}

HCC: Hepatocellular carcinoma; OS: Overall survival; RFS: Recurrence-free survival; HR: Hazard ratio; RR: Pooled risk ratio; RES: Surgical resection; RFA: Radiofrequency ablation; AEs: Adverse events; HFSR: Hand-foot skin reaction

\section{Acknowledgements}

We acknowledge and appreciate our colleagues for their valuable efforts and comments on this paper. We thank Liwen Bianji (Edanz) (www.liwenbianji. $\mathrm{cn} /$ ) for editing the language of a draft of this manuscript.

\section{Authors' contributions}

SH designed the study and drafted the manuscript. SH and DL were responsible for the collection and analysis of the research information. LZ, LS, and JW critically and carefully revised this manuscript. The authors read and approved the final manuscript.

\section{Funding}

Not applicable.

\section{Availability of data and materials}

The data and materials were obtained and analyzed from the current study or acquired from the corresponding author on reasonable request.

\section{Declarations}

Ethics approval and consent to participate

Not applicable.

\section{Consent for publication}

Not applicable.

\section{Competing interests}

The authors declare that they have no competing interests.

\section{Author details}

'Department of Oncology, The Second Affiliated Hospital of Nanchang University, No. 1, Minde Road, Nanchang 330006, Jiangxi Province, People's Republic of China. ${ }^{2}$ Department of Gynaecology, The Second Affiliated Hospital of Nanchang University, No. 1, Minde Road, Nanchang 330006, Jiangxi Province, People's Republic of China.

Received: 12 March 2021 Accepted: 28 May 2021

Published online: 10 June 2021

\section{References}

1. Akinyemiju T, Abera S, Ahmed M, Alam N, Alemayohu MA, Allen C, et al. The burden of primary liver cancer and underlying etiologies from 1990 to 2015 at the global, regional, and national level: results from the Global Burden of Disease Study 2015. JAMA Oncol. 2017;3(12):1683-91. https://doi. org/10.1001/jamaoncol.2017.3055.

2. Villanueva A, Longo DL. Hepatocellular carcinoma. New Engl J Med. 2019; 380(15):1450-62. https://doi.org/10.1056/NEJMra1713263.

3. Tan CK, Law NM, Ng HS, Machin D. Simple clinical prognostic model for hepatocellular carcinoma in developing countries and its validation. J Clin Oncol. 2003;21(12):2294-8. https://doi.org/10.1200/JCO.2003.03.151.

4. Geoff Farrell, Henry L-Y Chan, Man-Fung Yuen, et al. Prevention of hepatocellular carcinoma in the Asia-Pacific region: consensus statements. J Gastroenterol Hepatol. 2010;25(4):657-63.

5. Cucchetti A, Piscaglia F, Cescon M, Colecchia A, Ercolani G, Bolondi L, et al. Cost-effectiveness of hepatic resection versus percutaneous radiofrequency ablation for early hepatocellular carcinoma. J Hepatol. 2013;59(2):300-7. https://doi.org/10.1016/j.jhep.2013.04.009.

6. Deng Z, Jin Z, Qin Y, Wei M, Wang J, Lu T, et al. Efficacy of the association liver partition and portal vein ligation for staged hepatectomy for the treatment of solitary huge hepatocellular carcinoma: a retrospective singlecenter study. World J Surg Oncol. 2021;19(1):95. https://doi.org/10.1186/s12 957-021-02199-1.

7. Shimada S, Kamiyama T, Orimo T, Nagatsu A, Asahi Y, Sakamoto Y, et al. Prognoses, outcomes, and clinicopathological characteristics of very elderly 
patients with hepatocellular carcinoma who underwent hepatectomy World J Surg Oncol. 2020;18(1):122. https://doi.org/10.1186/s12957-020-01899-4.

8. Huang J, Yan L, Cheng Z, Wu H, Du L, Wang J, et al. A randomized trial comparing radiofrequency ablation and surgical resection for HCC conforming to the Milan criteria. Ann Surg. 2010;252(6):903-12. https://doi org/10.1097/SLA.0b013e3181efc656.

9. Lu LC, Cheng AL, Poon RT. Recent advances in the prevention of hepatocellular carcinoma recurrence. Semin Liver Dis. 2014;34(4):427-34. https://doi.org/10.1055/s-0034-1394141.

10. Sarici B, Isik B, Yilmaz S. Management of recurrent HCC after liver transplantation. J Gastrointest Cancer. 2020;51(4):1197-9. https://doi.org/10.1 007/s12029-020-00498-6

11. Zhang X-P, Chai Z-T, Gao Y-Z, Chen Z-H, Wang K, Shi J, et al. Postoperative adjuvant sorafenib improves survival outcomes in hepatocellular carcinoma patients with microvascular invasion after Ro liver resection: a propensity score matching analysis. HPB. 2019;21(12):1687-96.

12. Huang Y, Zhang Z, Zhou Y, Yang J, Hu K, Wang Z. Should we apply sorafenib in hepatocellular carcinoma patients with microvascular invasion after curative hepatectomy? Onco Targets Ther. 2019;12:541-8. https://doi. org/10.2147/OTT.S187357.

13. Liao Y, Zheng Y, He W, Li Q, Shen J, Hong J, et al. Sorafenib therapy following resection prolongs disease-free survival in patients with advanced hepatocellular carcinoma at a high risk of recurrence. Oncol Lett. 2017;13(2): 984-92. https://doi.org/10.3892/ol.2016.5525.

14. Wang SN, Chuang SC, Lee KT. Efficacy of sorafenib as adjuvant therapy to prevent early recurrence of hepatocellular carcinoma after curative surgery: a pilot study. Hepatol Res. 2014;44(5):523-31. https://doi.org/10.1111/ hepr.12159.

15. Teng CL, Hwang WL, Chen YJ, Chang KH, Cheng SB. Sorafenib for hepatocellular carcinoma patients beyond Milan criteria after orthotopic liver transplantation: a case control study. World J Surg Oncol. 2012;10(1):41. https://doi.org/10.1186/1477-7819-10-41.

16. Bruix J, Takayama T, Mazzaferro V, Chau G-Y, Yang J, Kudo M, et al. Adjuvant sorafenib for hepatocellular carcinoma after resection or ablation (STORM): a phase 3, randomised, double-blind, placebo-controlled trial. Lancet Oncol. 2015:16(13):1344-54. https://doi.org/10.1016/S1470-2045(15)00198-9.

17. Shen PC, Gao ZQ, Li DY, Tang Z. Effect of sorafenib and prophylactic TACE for prevention of postoperative relapse in patients with liver cancer combined with microvascular invasion. Zhonghua Gan Zang Bing Za Zhi. 2020;28(5):416-20. https://doi.org/10.3760/cma.j.cn501113-20190917-00338.

18. Wang D, Jia W, Wang Z, Wen T, Ding W, Xia F, et al. Retrospective analysis of sorafenib efficacy and safety in Chinese patients with high recurrence rate of post-hepatic carcinectomy. Onco Targets Ther. 2019;12:5779-91. https://doi.org/10.2147/OTT.S168447.

19. Zhuang L, Wen T, Xu M, Yang J, Wang W, Wu H, et al. Sorafenib combined with hepatectomy in patients with intermediate-stage and advanced hepatocellular carcinoma. Arch Med Sci. 2017;13(6):1383-93. https://doi. org/10.5114/aoms.2017.71066.

20. Xia F, Wu LL, Lau WY, Huan HB, Wen XD, Ma KS, et al. Adjuvant sorafenib after heptectomy for Barcelona Clinic Liver Cancer-stage C hepatocellular carcinoma patients. World J Gastroenterol. 2016;22(23):5384-92. https://doi. org/10.3748/wjg.v22.i23.5384.

21. Li J, Hou Y, Cai X-B, Liu B. Sorafenib after resection improves the outcome of BCLC stage C hepatocellular carcinoma. World J Gastroenterol. 2016; 22(15):4034-40. https://doi.org/10.3748/wjg.v22.i15.4034.

22. Antoniou EA, Margonis GA, Amini N, Anastasiou M, Angelou A, Kim Y, et al. Sorafenib as an adjuvant therapy for resectable hepatocellular carcinoma: a single center experience. J buon. 2016;21(5):1189-94.

23. Chen B, Pan C, Chen S, et al. Clinical efficacy of sorafenib in preventing recurrence of primary liver cancer after radical surgery. Chinese Journal of Hepatic Surgery. 2016;5(01):38-42.

24. Zhang W, Zhao G, Wei K, Zhang Q, Ma W, Song T, et al. Adjuvant sorafenib reduced mortality and prolonged overall survival and post-recurrence survival in hepatocellular carcinoma patients after curative resection: a single-center experience. Biosci Trends. 2014;8(6):333-8. https://doi.org/10 5582/bst.2014.01120

25. Li Z, Gao J, Zheng SM, Wang Y, Xiang X, Cheng Q, et al. The efficacy of sorafenib in preventing hepatocellular carcinoma recurrence after resection: a systematic review and meta-analysis. Rev Esp Enferm Dig. 2020;112(3): 201-10. https://doi.org/10.17235/reed.2020.6458/2019.
26. Cheng AL, Kang YK, Chen Z, Tsao CJ, Qin S, Kim JS, et al. Efficacy and safety of sorafenib in patients in the Asia-Pacific region with advanced hepatocellular carcinoma: a phase III randomised, double-blind, placebocontrolled trial. Lancet Oncol. 2009;10(1):25-34. https://doi.org/10.1016/S14 70-2045(08)70285-7.

27. Cheng Z, He L, Guo Y, Song Y, Song S, Zhang L. The combination therapy of transarterial chemoembolisation and sorafenib is the preferred palliative treatment for advanced hepatocellular carcinoma patients: a meta-analysis. World J Surg Oncol. 2020;18(1):243. https:/doi.org/10.1186/s12957-020-02017-0.

28. Kermiche-Rahali S, Di Fiore A, Drieux F, Di Fiore F, François A, Scotté M. Complete pathological regression of hepatocellular carcinoma with portal vein thrombosis treated with sorafenib. World J Surg Oncol. 2013;11(1):171. https://doi.org/10.1186/1477-7819-11-171.

29. Feng YX, Wang T, Deng YZ, Yang P, Li JJ, Guan DX, et al. Sorafenib suppresses postsurgical recurrence and metastasis of hepatocellular carcinoma in an orthotopic mouse model. Hepatology. 2011;53(2):483-92. https://doi.org/10.1002/hep.24075.

30. Wang Z, Hu J, Qiu SJ, Huang XW, Dai Z, Tan CJ, et al. An investigation of the effect of sorafenib on tumour growth and recurrence after liver cancer resection in nude mice independent of phosphorylated extracellular signalregulated kinase levels. Expert Opin Investig Drugs. 2011;20(8):1039-45. https://doi.org/10.1517/13543784.2011.588598

31. Brunetti O, Gnoni A, Licchetta A, Longo V, Calabrese A, Argentiero A, et al. Predictive and Prognostic Factors in HCC Patients Treated with Sorafenib. Medicina (Kaunas). 2019;55(10):707-23.

32. Hu B, Yang XR, Xu Y, Sun YF, Sun C, Guo W, et al. Systemic immuneinflammation index predicts prognosis of patients after curative resection for hepatocellular carcinoma. Clin Cancer Res. 2014;20(23):6212-22. https:// doi.org/10.1158/1078-0432.CCR-14-0442.

33. Hong YM, Yoon KT, Hwang TH, Heo J, Woo HY, Cho M. Changes in the neutrophil-to-lymphocyte ratio predict the prognosis of patients with advanced hepatocellular carcinoma treated with sorafenib. Eur J Gastroenterol Hepatol. 2019;31(10):1250-5. https://doi.org/10.1097/MEG. 0000000000001405.

34. Bruix J, Cheng AL, Meinhardt G, Nakajima K, De Sanctis Y, Llovet J. Prognostic factors and predictors of sorafenib benefit in patients with hepatocellular carcinoma: analysis of two phase III studies. J Hepatol. 2017. 67(5):999-1008. https://doi.org/10.1016/j.jhep.2017.06.026.

35. Wang $P$, Tan G, Zhu M, Li W, Zhai B, Sun X. Hand-foot skin reaction is a beneficial indicator of sorafenib therapy for patients with hepatocellular carcinoma: a systemic review and meta-analysis. Expert Rev Gastroenterol Hepatol. 2018;12(1):1-8. https://doi.org/10.1080/17474124.2017.1373018.

36. Horwitz E, Stein I, Andreozzi M, Nemeth J, Shoham A, Pappo O, et al. Human and mouse VEGFA-amplified hepatocellular carcinomas are highly sensitive to sorafenib treatment. Cancer Discov. 2014;4(6):730-43. https:// doi.org/10.1158/2159-8290.CD-13-0782.

37. Tsuchiya K, Asahina Y, Matsuda S, Muraoka M, Nakata T, Suzuki Y, et al. Changes in plasma vascular endothelial growth factor at 8 weeks after sorafenib administration as predictors of survival for advanced hepatocellular carcinoma. Cancer. 2014;120(2):229-37. https://doi.org/10.1 002/cncr.28384

\section{Publisher's Note}

Springer Nature remains neutral with regard to jurisdictional claims in published maps and institutional affiliations.

Ready to submit your research? Choose BMC and benefit from:

- fast, convenient online submission

- thorough peer review by experienced researchers in your field

- rapid publication on acceptance

- support for research data, including large and complex data types

- gold Open Access which fosters wider collaboration and increased citations

- maximum visibility for your research: over $100 \mathrm{M}$ website views per year

At $\mathrm{BMC}$, research is always in progress.

Learn more biomedcentral.com/submissions 